\title{
Optimization of the design of relay valves for rail vehicles braking systems in the context of train traffic safety
}

\author{
Sylwin Tomaszewski ${ }^{1}$, Franciszek Tomaszewski ${ }^{2,}$, Włodzimierz Stawecki ${ }^{1}$, Patryk Urbański ${ }^{2}$, and Mariusz Far ${ }^{1}$, and \\ Yaroslav Bolzhelarskyi ${ }^{3}$ \\ ${ }^{1}$ Łukasiewicz Research Network - Rail Vehicles Institute ”TABOR”, ul. Warszawska 181, 61-055 Poznań, Poland \\ ${ }^{2}$ Poznan University of Technology, Pl. Marii Skłodowskiej-Curie 5, 60-965 Poznań, Poland \\ ${ }^{3}$ Dnipro National University of Railway Transport named after Academician V. Lazaryan,, Lviv branch, 79052 Lviv, I. Blazhkevich \\ Street, 12a, Ukraine
}

\begin{abstract}
The article presents the functions of the relay valve and its place in brake systems of rail vehicles. The relay valve were divided according to their type, the structure and principle of their operation were discussed, and examples of rail vehicles and modules in which relay valves are installed are presented. Because of their function in braking systems the relay valves should be characterized by high reliability and correct carrying out the tasks in the braking system of rail vehicles. The article describes selected structural factors affecting the operation of the relay valve and which are important for ensuring the safety of train traffic. Such factors are the lubricants used in the relay valves and the way of controlling it simultaneously with two signals with the function of an alternative that eliminates unreliable elements of the braking system. The analysis of the test results of the lubricant parameters and the testing of the relay valves on the test bench showed that the correctness of the relay valves depends essentially on the properties of the lubricant used, especially at low temperatures. On the basis of the tests carried out, a grease was selected that at low temperatures meets the criteria for correct and reliable operation of relay valves in rail vehicles. In terms of the control method, a comparison of two control signal delivery systems to the relay valve has been made, a new design solution is presented that ensures greater operational reliability and thus greater safety of the train traffic.
\end{abstract}

\section{Introduction}

The braking system is an indispensable element of every vehicle. It is used to reduce speed and stop the vehicle, especially in an emergency situation, in the shortest possible time and with the greatest certainty. It is also one of the basic vehicle systems and a key system in terms of ensuring safety for vehicle users as well as for people and objects in their surroundings. The failure of braking systems is one of the main causes of traffic accidents caused by motor vehicles. Therefore, ensuring the braking system's efficiency and reliability is the main goal at the stage of construction, manufacture and operation of all types of vehicles operating in the world. The basic transport branches, in which the aim is to ensure operational safety by maintaining the highest quality, efficiency and reliability of braking systems, are road transport and rail transport $[1,2,3]$.

The article provides a partial analysis of the brake system of rail vehicles. For the proper functioning of entire braking system in every vehicle, which is a part of the train set, there must be the suitable apparatus on it that receives the signals about braking or releasing of the brakes and standardized actuators in order to obtain similar braking performance of all wagons on the train. This applies to the most responsible braking devices, such as the distributor valve and the relay valve or relay valves of brake cylinders, emergency braking accelerator, weighing valve and anti-slip system [4]. The required parameters of the rail vehicle braking system are defined in the relevant UIC leaflets and European standards.

The article presents the exemplary of tests results carried out on the relay valve and describes relations between selected structural factors affecting the parameters it achieves, which have a direct impact on the maintaining of train traffic safety. On the basis of the obtained test results, directions of introducing appropriate changes in the technical documentation of the relay valves were proposed, which will ensure the fulfillment of current requirements during the operation and the increase the reliability of its operation, ensuring a high level of safety of the operated vehicles.

\section{Relay valve - types, construction and application}

The relay valve is a device used to amplify the pneumatic signal with the required pressure (through the control system) in the cylinder (s). In the rail vehicle brake system the relay valve can be installed at a some distance from the distributor valve on the separate bracket (Fig. 1) or on a common bracket with the

Corresponding author: franciszek.tomaszewski@put.poznan.pl 
distributor valve (so-called the compact system) or on the pneumatic board of the vehicle (wagon) [5].

Figures 2 and 3 present examples of relay valves from the relay valve family for filling the vehicle brake cylinders of traction units.

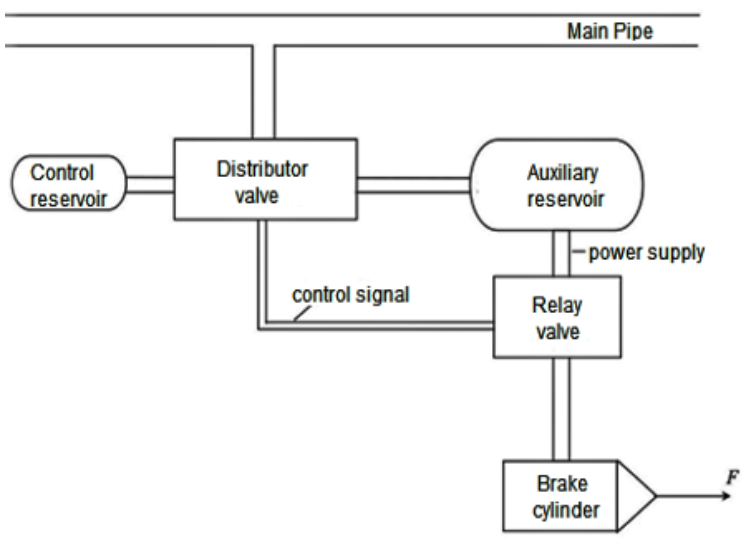

Fig. 1. Location of the relay valve in the rail vehicle brake system [5]

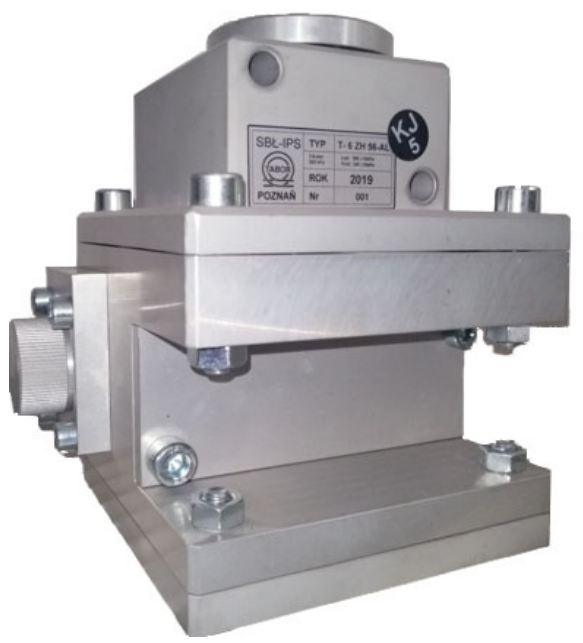

Fig. 2. Relay valve for filling the brake cylinders with regulated ratio

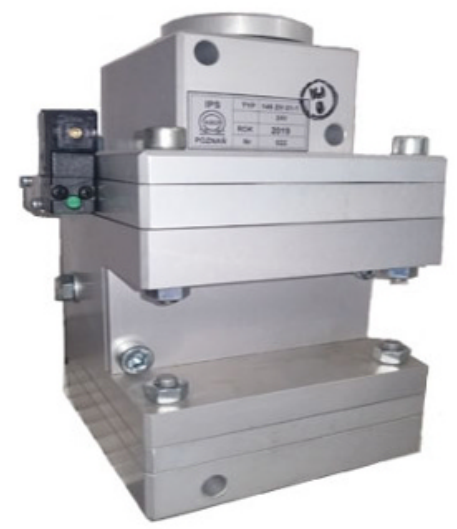

Fig. 3. Double stage relay valve for filling the brake cylinders with regulated ratio and with two control signals

The division of relay valves by types is defined by the European norm EN 15611+A1 [6]:
1. Single stage relay valve type A

Relay valve with one fixed ratio, where the ratio can be less, equal or greater than 1 .

2. Multi stage relay valve type B

Relay valve with more than one fixed ratio, where the ratios can be less, equal or greater than 1 .

3. Relay valve type B1

Multi stage relay valve that can change ratio during a brake application.

4. Relay valve type B2

Multi stage relay valve where a change of ratio cannot take place during a brake application.

5. Empty/load relay valve

Specific type of multi stage relay valve (type B1 or B2) with only two stages, giving an empty (tare) or a loaded output pressure proportional to input pressure dependant on the load signal input.

6. Variable load relay valve type C

Relay valve with a continuously changeable ratio, where a load signal is used to change the ratio.

7. Multi stage variable load relay valve type $\mathrm{C} 1$

Relay valve with a continuously changeable ratio, where a load signal is used to change the ratio and with a multi stage feature added.

8. Two (multi) input relay valve type D

Relay valve (type A, B or C) with two (or more) input pressure, controling a single output pressure.

9. Variable load relay valve with kinked characteristic type E

Variable load relay valve (type C) with a special nonlinear characteristic, with automatically comes into operation when the vehicle has more than a certain load.

The relay valves presented in Figures 2 and 3 are mainly used in braking systems of modernized Electric Traction Units (Fig. 4) and modern locomotives. The relay valves developed and made at the Łukasiewicz Research Network - Rail Vehicles Institute "TABOR" are usually mounted as the modular apparatus on the pneumatic brake boards of rail vehicles (Fig. 5, 6).

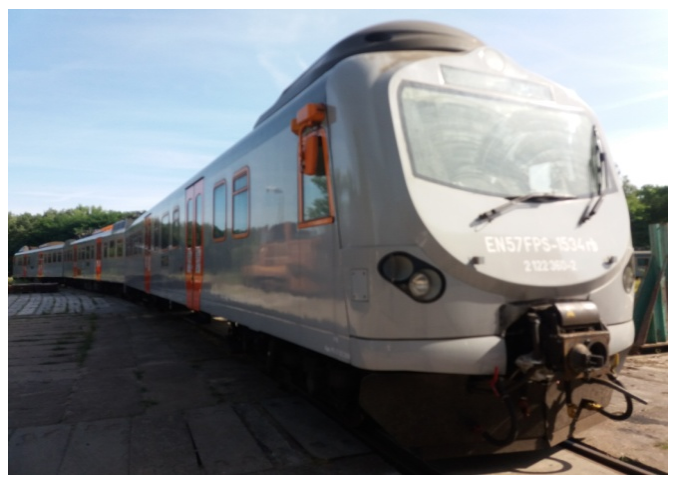

Fig. 4. The Electric Traction Unit EN57 after modernization

In the relay valve construction (Fig. 7) a number of solutions based on actuators, such as pistons sealed with diaphragm transferring the appropriate forces, valves with a rubber O-ring and U-type sealing rings, springs and a precise piston-slide system with a rolling diaphragm the smooth change of pressure in the cylinders as a function of the load. In the construction of this relay valve it is provided for a very wide range of 
regulation of its parameters in order to adjust its characteristics to different needs and types of rail vehicles [5].

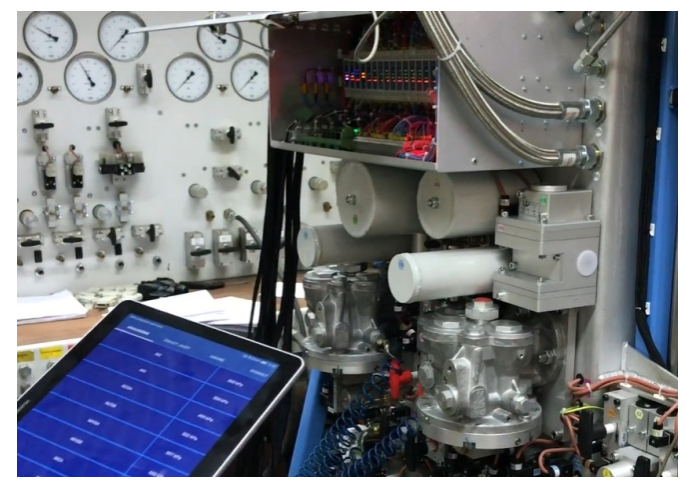

Fig. 5. The modular pneumatic brake board of rail vehicle

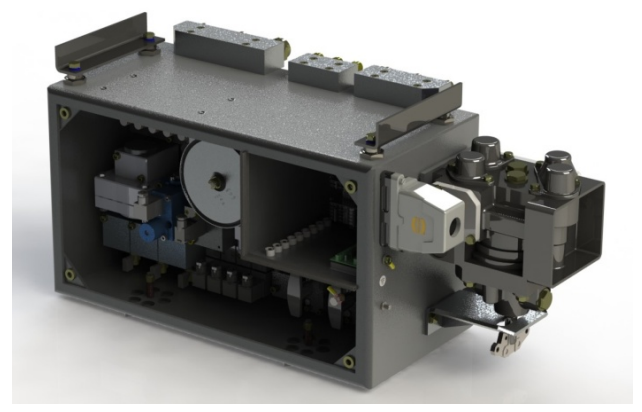

Fig. 6. The modular pneumatic brake board of rail vehicle

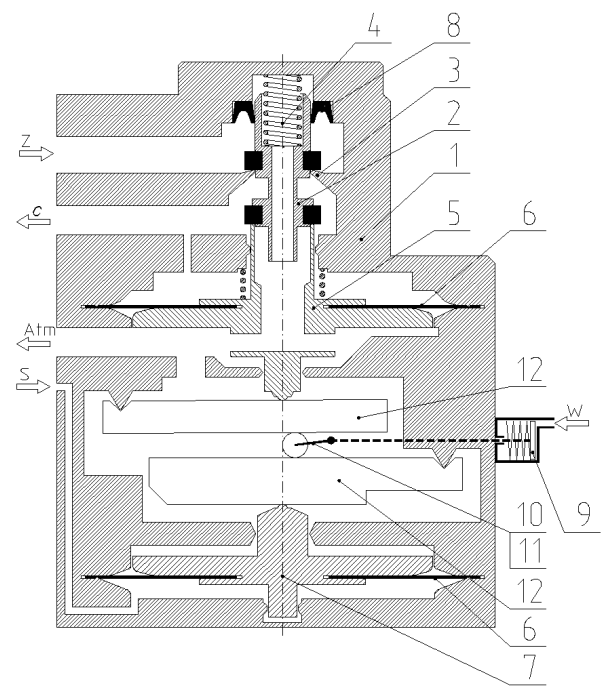

Fig. 7. An illustrative construction of the single stage pressure transformer developed by Łukasiewicz Research Network Rail Vehicles Institute "TABOR" [7]

( $\mathrm{Z}$ - power supply, $\mathrm{C}$ - cylinder, $\mathrm{S}$ - control signal, $\mathrm{W}$ - pneumatic signal of the weight of the vehicle, 1 - relay valve body, 2 - filling valve, 3 - valve seat, 4 - spring, 5 - upper piston with a venting rod, 6 - membrane, 7 - lower piston, 8 - sealing ring, 9 - piston - slide system, 10 - roller, 11 - inclined swing lever, 12 - levers)

The main element of the relay valve consists of a venting rod connected to the piston (5) and the diaphragm (6). It moves in the body (1), up or down depending on the pressure difference occurring on both sides of the diaphragm (6). The supply air (Z) from the auxiliary reservoirs is constantly supplied to each relay valve. When the distributor valve generates a control signal (S), which reaches to the chamber under the lower piston (7) and diaphragm (6), the piston (7) moves upwards and the rod (5) opens the valve (2) via the lever (12), which allows the supply air to enter onto the output side (C) of the relay valve to the brake cylinder capacity. In the opposite situation, when the control signal (S) decreases, the valve closes the supply flow $(Z)$, and the air on the output side $(C)$ of relay valve escapes from the cylinder into the atmosphere through the hollow rod. The pneumatic signal of the weight of the vehicle (W) changes the lever ratio (12) between the pistons (7) and (5) $[5]$

\section{Impact of the applied lubricants on relay valve operation}

To meet the requirements demanded from the relay valves with a complicated structure, it is essential to make their subassemblies very precisely and to assemble and adjust them carefully. Because of observation of a certain scatter of the relay valve parameters, there was a need to carry out the detailed tests, allowing to determine the influence factors and optimize the structure in order to ensure the highest possible repeatability and reliability of operation of the relay valves. One of the selected factors of influence was the type of lubricants used in the relay valves [7].

During the analysis of the operation (functioning) of the relay valves in operation in winter, it was found that there was the increase of failure of these devices during this period. Therefore, it was decided to carry out the correctness tests of the relay valves operation at sub-zero temperatures.

During the tests of the relay valve in the climatic chamber it was observed that the type of the used grease had the influence on the operation of the relay valve at different temperatures due to the changes in the resistances of motion. Therefore, three selected types of lubricants were tested in a climatic chamber [7].

The lubricant tests were carried out in the Laboratory for Exploitation Materials of the Poznan University of Technology. The measured parameter was the consistency of the lubricant, specifically its hardness index. For the measurements of the hardness of lubricants, a PL-12DC laser penetrometer, manufactured by the Institute for Sustainable Technologies - National Research Institute in Radom, was used, shown in Figure 8.

The laser penetrometer allows to determine the consistency of the grease. The correct consistency must ensure that the grease does not generate too high resistances. The consistency is graded according to the scale developed by the NLGI (National Lubricating Grease Institute) presented in Table 1. The softer is the grease the lower number is on the scale. During the test, the depth of penetration of the standard cone into a sample of grease is measured in tenths of a millimeter (Fig. 9). 


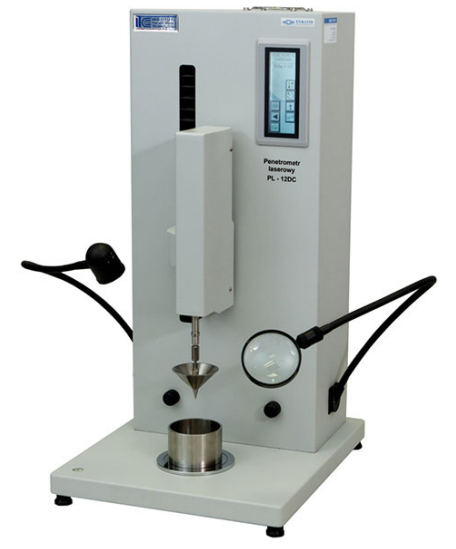

Fig. 8. Laser penetrometer PL-12DC [7]

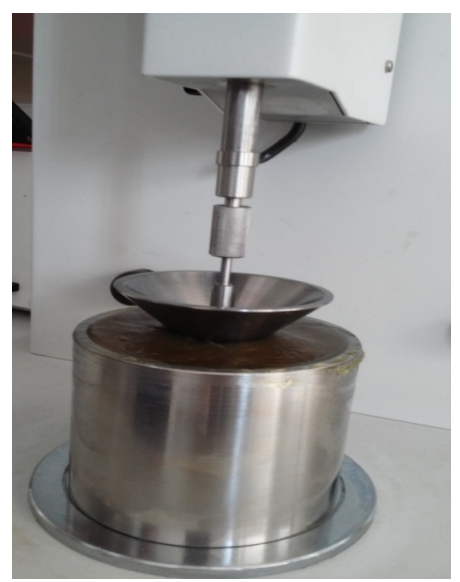

Fig. 9. Laser penetrometer PL-12DC - view during the test [7]

It is an automatic device, in which it is used the modern laser technology to measure the penetration. The penetrometer is intended, among others, for testing the consistency of petrochemical products (e.g. lubricants, asphalts, paraffins), food products, cosmetic products, as well as mortars and plastic explosives [8,9].

Table 1. Classification of greases under NLGI consistency class [7]

\begin{tabular}{|c|c|l|}
\hline $\begin{array}{c}\text { Number } \\
\text { NLGI }\end{array}$ & $\begin{array}{c}\text { Penetration } \\
\text { according to ASTM } \\
\left(\mathbf{1 0}^{-1} \mathbf{m m}\right)\end{array}$ & $\begin{array}{c}\text { Appearance } \\
\text { at room } \\
\text { temperature }\end{array}$ \\
\hline 000 & $445-475$ & very liquid \\
\hline 00 & $400-430$ & liquid \\
\hline 0 & $355-385$ & semi-liquid \\
\hline 1 & $310-340$ & very soft \\
\hline 2 & $265-295$ & soft \\
\hline 3 & $220-250$ & medium hard \\
\hline 4 & $175-205$ & hard \\
\hline 5 & $130-160$ & very hard \\
\hline 6 & $85-115$ & extremely hard \\
\hline
\end{tabular}

The following lubricants popularly used in Łukasiewicz Research Network - Rail Vehicles Institute „TABOR” were tested:

- "Vecolit EPX 00" - semi-liquid gear lubricant and central lubrication,

- "Elf MULTI" - lithium calcium grease for bearings,

- "TF silikon + teflon" - silicone grease with the addition of Teflon.

The above lubricants were tested at three temperatures: $24^{\circ} \mathrm{C}$ (room temperature), $0^{\circ} \mathrm{C}$ and (- 26 $\left.{ }^{\circ} \mathrm{C}\right)$, which were obtained using a laboratory freezer [7].

The results of the tests carried out in the laboratory are listed in Table 2. A graphical image of the change of the consistency of various greases as a function of temperature is shown in Figure 10.

Table 2. The test results of greases consistency as a function of temperature [7]

\begin{tabular}{|l|c|c|c|c|c|c|c|c|c|}
\hline Name of lubricant & \multicolumn{3}{|c|}{ Vecolit EPX 00 } & \multicolumn{3}{c|}{ Elf MULTI } & \multicolumn{3}{c|}{ TF silikon + teflon } \\
\hline Temperature & $-26{ }^{\circ} \mathrm{C}$ & $0{ }^{\circ} \mathrm{C}$ & $24{ }^{\circ} \mathrm{C}$ & $-26{ }^{\circ} \mathrm{C}$ & $0{ }^{\circ} \mathrm{C}$ & $24{ }^{\circ} \mathrm{C}$ & $-26{ }^{\circ} \mathrm{C}$ & $0{ }^{\circ} \mathrm{C}$ & $24{ }^{\circ} \mathrm{C}$ \\
\hline Measurement I & 157,4 & 359,8 & 443,2 & 126,0 & 242,1 & 273,1 & 284,3 & 290,0 & 308,8 \\
\hline Measurement II & 174,2 & 358,7 & 437,5 & 117,0 & 234,5 & 266,0 & 274,3 & 280,2 & 305,4 \\
\hline Measurement III & 160,7 & 369,7 & 446,0 & 136,1 & 229,4 & 263,8 & 290,4 & 291,4 & 306,1 \\
\hline Average & 164,1 & 362,7 & 442,2 & 126,4 & 235,3 & 267,6 & 283,0 & 287,2 & 306,8 \\
\hline
\end{tabular}

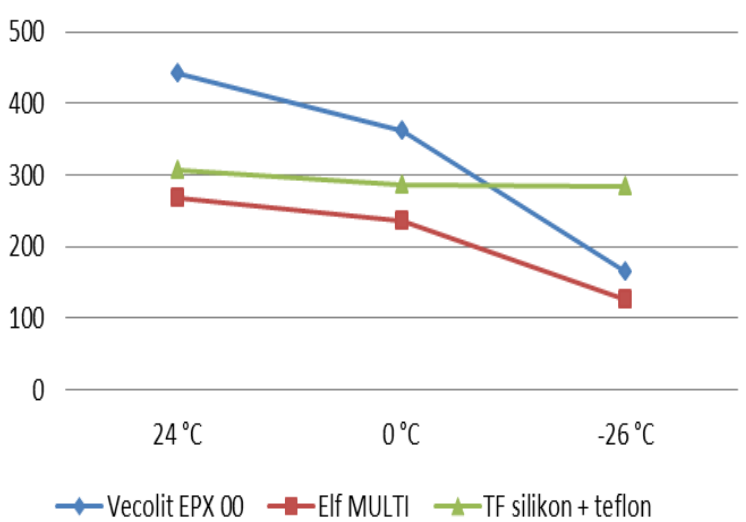

Fig. 10. Consistency of greases as a function of temperature [7]
Figure 11 shows the view of one of the relay valve's elements (valve) with the used Elf MULTI grease and Vecolit EPX 00 grease (used in the relay valve) at temperature $-26^{\circ} \mathrm{C}$. It is clearly seen that the used lubricants, under the influence of low sub-zero temperature, changed their consistency from the liquid into a solid consistency, which is disadvantageous for the correct operation of the relay valve [7].

The carried out tests have shown that this causes occurrence of large resistances of movement and leads to the suspension of the valve, and thus to the lack of full release of the cylinder (C) in response to the control signal (S), and the occurrence of large leak in the power supply system $(Z)$ of the braking system of the rail vehicle [7]. The pressure characteristics in the relay valve system during operation with frozen grease and the suspended valve are presented in Figure 12. 

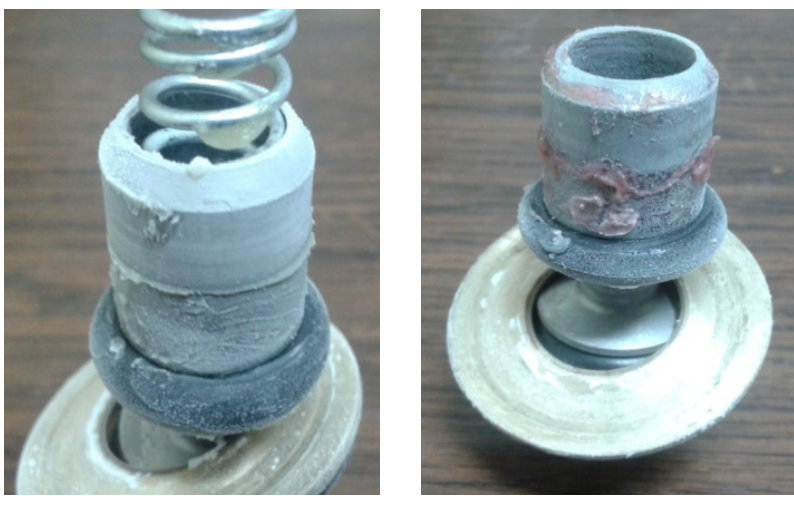

Fig. 11. View of the used Elf MULTI grease (on the left) and Vecolit EPX 00 grease (on the right) in the relay valve operating at temperature of $-26^{\circ}[7]$

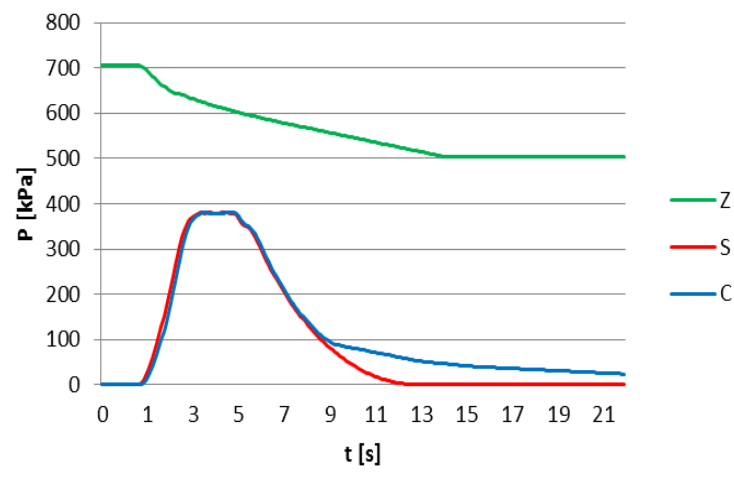

Fig. 12. Exemplary course of the test with a suspended valve of relay valve [7]

However, Figure 13 shows the valve with the used TF silicone + teflon grease, which during operation at $-26{ }^{\circ} \mathrm{C}$ did not change its consistency and thus provided the correct operation of the relay valve at the sub-zero temperatures.

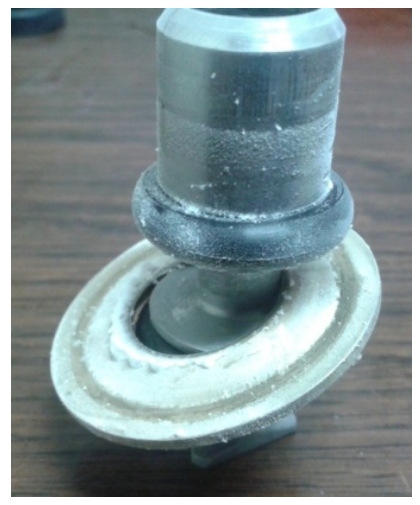

Fig. 13. View of the used TF silikon + teflon grease in the relay valve operating at temperature of $-26^{\circ} \mathrm{C}$ [7]

As a result of the above analysis of lubricants, the previously used Elf MULTI grease for TF silicone + teflon grease has been changed. However, further observations of pressure transformers during operation have shown that this grease adversely affects the operation of the relay valve systems having elements made of silicone rubber (piston diaphragms, rubber bellows). Therefore, it was selected the grease, which used in the specific elements of the relay valve construction allows it to function correctly and reliably.

\section{Elimination of unreliable elements of the rail vehicles braking system}

As already mentioned above, the basic element of pneumatic brake systems of railway vehicles is the relay valve supplied from the auxiliary tank with compressed air, filling brake cylinders during braking. In brake systems of traction units or pre-defined vehicles, the cylinder relay valve is controlled by pneumatic signals coming from the pneumatic brake control system (from the distributor valve) and from the electro-pneumatic brake system. In locomotives, the cylinder relay valve can be controlled by a signal from the distributor valve and from the direct auxiliary brake system.

Until now, the most commonly used system was a relay valve controlled by a signal from these two sources through a double-return valve realizing the alternative function (Fig. 14). This arrangement ensures the cylinder pressure on the vehicle due to a stronger control signal.

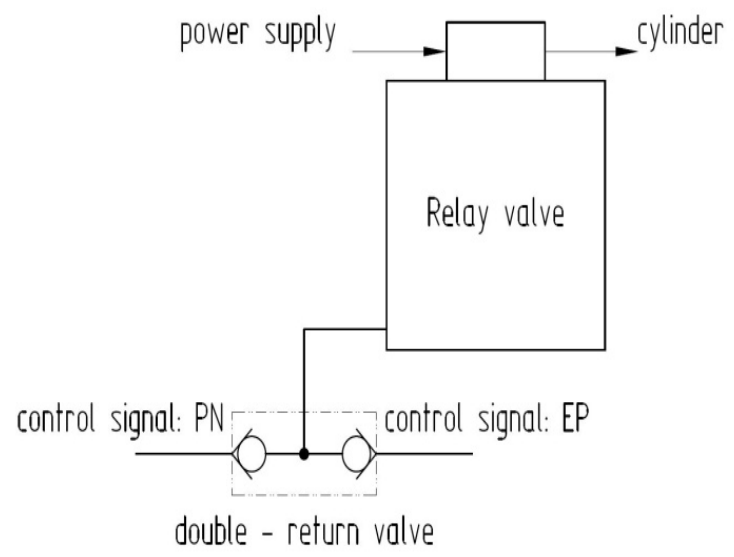

Fig. 14. Diagram of supplying a control signal to the relay valve with a double-return valve

Experience collected as a result of many years of observation, many double-return valves in operation has shown that they sometimes fail, reducing the reliability of the entire system. These failures occurred as a result of slight contamination of the valve or loss of lubricating grease after a long service life. As part of the ongoing development work on increasing the functionality and reliability of the braking equipment in Łukasiewicz Research Network - Rail Vehicles Institute "TABOR", a control system for a relay valve controlled from two sources with an alternative function was developed, in which the commonly known and used double-return valve was completely eliminated from this system. A relay valve with two control pistons was developed (Fig.15), the lower control piston being a moving piston relative to the upper control piston.

Thanks to this solution, it was possible to simplify the relay valve control system by eliminating the doublereturn valve (Fig.16) and to ensure greater reliability of the system, because the newly developed control system based on two control pistons is completely resistant to 
dirt that immobilized the double-return valve and does not require special lubrication, which ensures correct operation of the brake system in the long-term operation of the vehicle between inspection repairs.

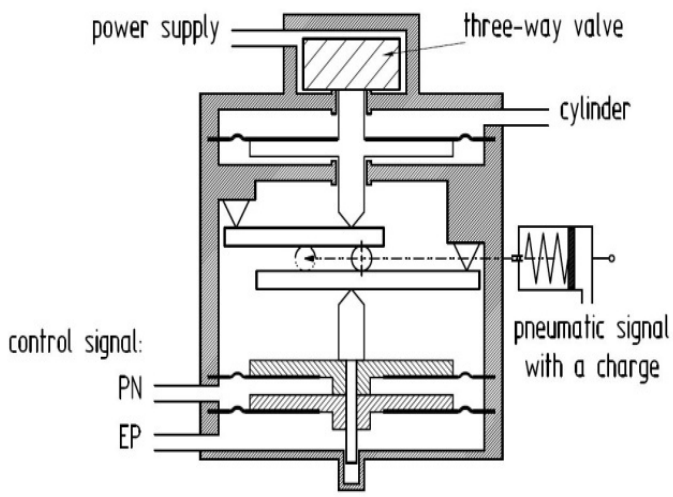

Fig. 15. Construction of the relay valve with a control system with an alternative function

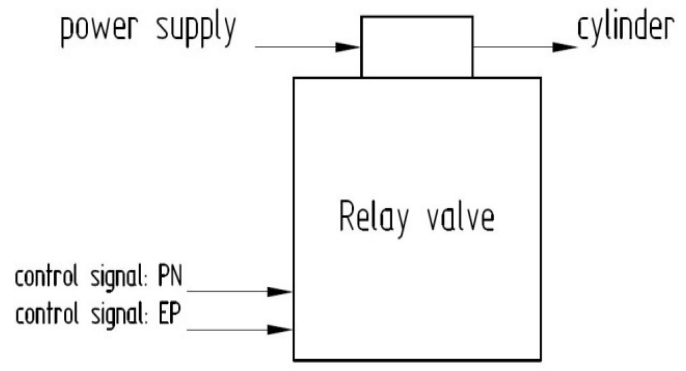

Fig. 16. Diagram of supplying a control signal to the relay valve with an alternative function

Any interruption in the delivery of the control signal causes that the rely valve will not work or will work incorrectly, which results in the lack or incorrect pressure in the brake cylinders and, consequently, no braking or lengthening its distance. This condition directly affects the reduction of train traffic safety.

\section{Conclusions}

Ensuring the safety of vehicle users as well as people and objects in their surroundings is the main and most important purpose of all vehicle builders. In particular for mass transport vehicles, such as rail vehicles, this is the topic with the highest priority. Therefore, every effort should be made to ensure that every element of the vehicle responsible for safety works with the greatest certainty and has a high reliability factor. In the case of a rail vehicle, such element is the cylinder relay valve located in the brake system.

The relay valves as one of the most responsible elements of the rail vehicle braking system are subjected to continuous analyzes in Łukasiewicz Research Network - Rail Vehicles Institute "TABOR" in order to improve the structure and improve the reliability of their operation. The article identifies two structural factors that are important for the optimization of the structure in the direction of improving the operational reliability and thus ensuring the safety of train traffic.

One of these factors was the applied lubricant. Therefore presented the test results of lubricants in order to select the lubricant with the best parameters as a function of temperature, in application to the relay valve. During the analysis of the test results it was found that the grease used in the relay valve must have the stable parameters in the wide range of temperatures. Especially at low temperatures, it must keep as liquid consistency as possible. Therefore, the silicone grease was introduced in the appropriate systems of relay valve, which has a practically constant consistency in the range of temperature from $-30{ }^{\circ} \mathrm{C}$ to $+40{ }^{\circ} \mathrm{C}$. On the basis of the carried out tests the grease was selected, which used in the specific elements of the relay valve construction allows it to function correctly and reliably, and thus guarantees reliable operation of the rail vehicle brake system.

The second factor was the method of controlling the relay valve with two control signals from the alternative function, the use of which eliminated the unreliable system with a double-return valve. Such a solution not only ensures greater reliability of the braking system and increases train safety, but also simplifies the construction of this system.

\section{References}

1. Tomaszewski F., Tomaszewski S.: RAIL VEHICLES, Volume: 4, Pages: 1-10, Published: (2015)

2. J. Merkisz, L. Rymaniak, EKSPLOATACJA I NIEZAWODNOSC-MAINTENANCE AND RELIABILITY, Volume: 19, Issue: 4, Pages: 522529, DOI: 10.17531/ein.2017.4.5, Published: (2017)

3. P. Daszkiewicz, M. Andrzejewski, MATEC Web of Conferences, Volume: 118, Article Number: UNSP 00014, DOI: 10.1051/matecconf/201711800014, Published: (2017)

4. Kaluba M.: PROCEEDINGS OF THE INSTITUTE OF VEHICLES. Volume: 1(60), Published: (2006)

5. Tomaszewski F., Tomaszewski S.: RAIL VEHICLES, Volume: 4, Pages: 14-19, Published: (2014)

6. EN 15611+A1: Railway applications - Braking Relay valves, (2011)

7. Tomaszewski S., Tomaszewski F., Strzemkowski J.: RAIL VEHICLES, Volume: 3, Pages: 18-24, Published: (2018)

8. M. Andrzejewski, D. Gallas, P. Daszkiewicz, A. Merkisz-Guranowska, H. Stawecka, MATEC Web of Conferences, Volume: 118, Article Number: UNSP 00015, DOI: 10.1051/matecconf/201711800015, Published: (2017)

9. L. Rymaniak, MATEC Web of Conferences, Volume: 118, Article Number: UNSP 00009, DOI: 10.1051/matecconf/201711800009, Published: (2017) 